Research Article

\title{
Parameter Estimation and Applications of the Weibull Distribution for Strength Data of Glass Fiber
}

\author{
Yuxuan Wu, ${ }^{1}$ Hanyang Xie, ${ }^{1}$ Jyun-You Chiang $\mathbb{D}^{1},{ }^{1}$ Gang Peng, ${ }^{1}$ and Yan Qin ${ }^{2}$ \\ ${ }^{1}$ School of Statistics, Southwestern University of Finance and Economics, Chengdu 611130, China \\ ${ }^{2}$ School of Foreign Languages for Business, Southwestern University of Finance and Economics, Chengdu 611130, China \\ Correspondence should be addressed to Jyun-You Chiang; joe8911211@gmail.com
}

Received 18 May 2021; Revised 5 August 2021; Accepted 7 September 2021; Published 22 September 2021

Academic Editor: Francesco Zammori

Copyright (c) 2021 Yuxuan Wu et al. This is an open access article distributed under the Creative Commons Attribution License, which permits unrestricted use, distribution, and reproduction in any medium, provided the original work is properly cited.

Glass fiber is a good substitute for metal materials. However, in the process of manufacturing, it is necessary to carry out sampling inspection on its tensile strength to infer its quality. According to previous literatures, the strength data can be well fitted by the Weibull distribution, while the poor parameter estimation method cannot obtain reliable analysis results. Therefore, a new parameter estimation method is proposed. Based on the simulation results, it is found that the proposed parameter estimation method outperforms the other competitors to obtain reliable estimates of the Weibull parameters. Finally, the proposed parameter estimation method is applied to two real data sets of glass fiber strength for illustration. The results of data analysis show that our proposed parameter estimation method is more suitable for these data sets than other estimation methods.

\section{Introduction}

Glass fiber is a kind of high-performance composite fiber. Compared with carbon fiber, it has lower cost and wider application in the field of construction, electronics, chemical industry, and so on. In the manufacturing process of glass fiber, it is very important to determine the failure probability distribution of several nominally identical glass fiber samples by destructive test and then statistical analysis of their strength data. Figure 1 shows the typical fracture pattern for low strength fiber, which is from Feih et al. [1]. According to previous literatures, the strength data of fiber is usually described by two-parameter Weibull distribution. For example, Sakin and Ay [2] studied the bending fatigue properties of glass fiber reinforced polyester composite plates and fitted the data with two-parameter Weibull distribution. Acitas et al. [3] assumed that the strength data of glass fiber followed the Weibull distribution and estimated the parameters with maximum likelihood estimation (MLE). Zhu et al. [4] developed the technology of making high strength refractory ceramic fibers using fly ash, and the mechanical properties of a series of fly ash fibers were assessed by the Weibull distribution. Ferreira et al. [5] studied the Weibull analysis of tensile tested piassava fibers with different diameters.

Because of the good properties of the Weibull distribution, it is currently applied in various fields. Many researches have proposed the related distribution, neutrosophic statistics, or extended distribution and discussed its properties and applications, such as Alkarni et al. [6], Almongy et al. [7], Almetwally et al. [8], Ferretti et al. [9], Zhao et al. [10], Aslam et al. [11], Fernández et al. [12], Arif and Aslam [13], Aslam et al. [14], Aslam [15], Aslam et al. [16], Aslam and Arif [17], and Zhang et al. [18].

Before the reliability and failure rate of glass fiber are inferred, sample-based parameters' estimation is required for the analysis process. There are many methods for estimating the unknown parameters and reliability analysis of the Weibull distribution. Naresh et al. [19] provided reliability analysis of tensile strength of glass/epoxy and carbon/ epoxy composites based on the Weibull distribution. Malik et al. [20] evaluated reliability of a non-series-parallel system of seven components, and the Weibull distribution is used for the random variables associated with failure and operating times of the components. Jia [21] studied the reliability for the Weibull distribution with homogeneous heavily 


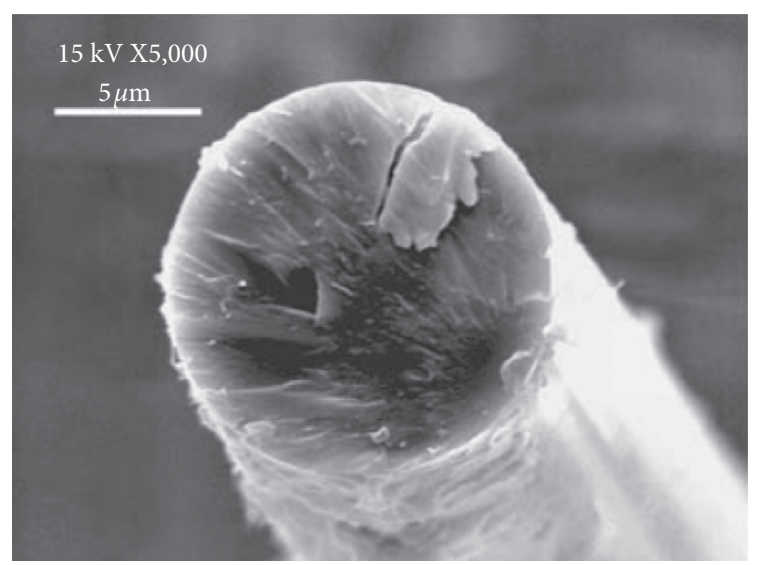

FIgURE 1: Low strength fracture surface of glass fiber.

censored data. Johnson et al. [22] introduced many commonly used estimation methods for the Weibull distribution in the book, such as MLE, moment estimation (MM), percentile method (PM), method of logarithmic moment (MLM), and Bayesian estimation. Teimouri et al. [23] proposed an L-moment (LM) estimator for the Weibull distribution. Kantar [24] proposed generalized least squares and weighted least squares estimation methods for distributional parameters. Datsiou and Overend [25] investigated four estimation methods of the Weibull distribution for glass strength data. Hidekazu et al. [26] proposed an improved estimation method for MLE, which improved the estimation of Weibull shape parameter, scale parameter, and quantile. Acitas et al. [3] used particle swarm optimization to solve the MLE of the Weibull distribution and applied the results to the strength data of glass fiber. Although the above literatures on parameter estimation and reliability analysis of the Weibull distribution are valuable, there is a lack of research on the parameter estimation method of strength data fitting the Weibull distribution (Datsiou and Overend [25]). The most commonly used estimation method is MLE, while it does not perform well for the Weibull distribution, especially in small samples.

The aim of this article is to propose a new parameter estimation method for the Weibull distribution. The performance of proposed method outperforms other common estimation methods for small sample size. In addition, the proposed estimation method is applied to estimate the reliability and failure rate of products to evaluate quality or reliability.

The rest of this paper is organized as follows. In Section 2, some existing parameter estimation methods for the Weibull distribution are addressed. In Section 3, we propose a new parameter estimation method for the Weibull distribution. Based on the proposed parameter estimation method, it is applied to the estimation of reliability and failure rate. In Section 4, a Monte Carlo simulation is conducted to evaluate the performances of the proposed parameter estimation method. Then, two real strength data sets of glass fiber are used to demonstrate the proposed parameter estimation method and reliability analysis in
Section 5, and some concluding remarks are provided in Section 6.

\section{Review of Parameter Estimation Methods}

Suppose the random variable $T$ has a Weibull distribution with shape parameter $\alpha>0$ and scale parameter $\beta>0$, denoted as $T \sim W D(\alpha, \beta)$. The probability density function (PDF), cumulative distribution function (CDF), reliability function (RF), and failure rate function (FRF) are, respectively, given by

$$
\begin{aligned}
f_{T}(t ; \alpha, \beta) & =\frac{\alpha}{\beta}\left(\frac{t}{\beta}\right)^{\alpha-1} e^{-(t / \beta)^{\alpha}}, t>0, \\
F_{T}(t ; \alpha, \beta) & =1-e^{-(t / \beta)^{\alpha}}, \quad t>0, \\
R(t) & =P(X>t)=e^{-(t / \beta)^{\alpha}}, \quad t>0, \\
\lambda(t) & =\frac{f_{X}(t ; \alpha, \beta)}{R(t)}=\frac{\alpha}{\beta}\left(\frac{t}{\beta}\right)^{\alpha-1}, \quad t>0 .
\end{aligned}
$$

We assume $T_{1}, \ldots, T_{n}$ is a random sample from the twoparameter Weibull distribution. Five common parameter estimation methods are reviewed as follows.

2.1. Method of Moments (MM). The MM is a traditional parameter estimation method, which is widely used for parameter estimation of various distributions. This estimation method assumes that the first $k$ population moments are equivalent to the first $k$ sample moments and estimates the unknown parameters by solving the equations derived from the equivalence relation. Therefore, it can be used for two-parameter Weibull distribution, whose parameter estimation satisfies the following two equations:

$$
\begin{aligned}
& \frac{\Gamma\left(2 / \widehat{\alpha}_{M M}+1\right)}{\left.\Gamma^{2}\left(1 / \widehat{\alpha}_{M M}+1\right)\right)}+\frac{\widehat{M}_{2}-\widehat{M}_{1}^{2}}{\widehat{M}_{1}}-1=0, \\
& \widehat{\beta}_{M M}=\frac{\widehat{M}_{1}}{\Gamma\left(1 / \widehat{\alpha}_{M M}+1\right)},
\end{aligned}
$$

where $\widehat{\alpha}_{M M}$ and $\widehat{\beta}_{M M}$ are the estimates of $\alpha$ and $\beta$, respectively, $\Gamma$ (.) is gamma function, and $\widehat{M}_{1}$ and $\widehat{M}_{2}$ are the first and second noncentral sample moments, respectively.

2.2. Method of L-Moment(LM). According to Teimouri et al. [23], they first proposed a $L$-moment estimator for twoparameter Weibull distribution. The LM estimator of parameters can be obtained by the following equations:

$$
\begin{aligned}
\widehat{\alpha}_{L M} & =-\frac{\ln (2)}{\ln \left(1-\left(2 / n(n-1) \sum_{i=1}^{n}(i-1) T_{i: n}-\bar{T}\right) / \bar{T}\right)}, \\
\widehat{\beta}_{L M} & =\frac{\bar{X}}{\Gamma\left(\left(1 / \widehat{\alpha}_{L M}\right)+1\right)},
\end{aligned}
$$


where $T_{i: n}$ denotes the $i$ th order statistic in the sample size $n$, and $\bar{T}$ is the average of sample $T_{i}, i=1, \ldots, n$.

2.3. Maximum Likelihood Estimator (MLE). The MLE method is one of the most commonly used parameter estimation methods. The MLE of two-parameter Weibull distribution can be obtained by the following equations:

$$
\begin{aligned}
& \widehat{\beta}_{M L E}=\frac{1}{n}\left(\sum_{i=1}^{n} t_{i}^{\alpha}\right)^{\alpha}, \\
& \frac{1}{\widehat{\alpha}_{M L E}}=\frac{\sum_{i=1}^{n} t_{i}^{\alpha} \ln \left(t_{i}\right)}{\sum_{i=1}^{n} t_{i}^{\alpha}}-\frac{1}{n} \sum_{i=1}^{n} \ln \left(t_{i}\right) .
\end{aligned}
$$

Since the close-form solution of the MLE is not available, some numerical optimization methods have been proposed to overcome this issue.

2.4. Method of Percentile (PM). According to Johnson et al. [22], the PM estimates of the two-parameter Weibull distribution are

$$
\begin{aligned}
& \widehat{\beta}_{P M}=\widehat{x}_{0.632}, \\
& \widehat{\alpha}_{P M}=\left(\frac{\ln [-\ln (1-p 2)]}{\ln \left(\hat{t}_{p}\right)-\ln \left(\widehat{t}_{0.632}\right)}\right),
\end{aligned}
$$

where $\widehat{t}_{p}$ and $\widehat{t}_{0.632}$ are the estimators of $p$ th and 0.632 th percentile, respectively. Former studies show that PM has a good estimation effect when $p=0.15$ or 0.31 .

\section{Proposed Parameter Estimation Method}

According to the distribution property, if $Y=F_{T}(t ; \alpha, \beta)$, then $Y$ becomes a uniform distribution from 0 to 1 . Moreover, the mean and variance of $Y$ are $1 / 2$ and $1 / 12$, respectively, which can be expressed as

$$
\begin{gathered}
\mu_{Y}=\frac{1}{2}, \\
\sigma_{Y}^{2}=\frac{1}{12} .
\end{gathered}
$$

Suppose $\left\{t_{1}, t_{2}, \ldots, t_{n}\right\}$ is a random sample with sample size $n$ from $W D(\alpha, \beta)$. Theoretically, $y_{i}=F_{T}\left(t_{i} ; \alpha, \beta\right), i=$ $1, \ldots, n$, also follows a uniform distribution from 0 to 1 . However, the sample has inevitable random error. Therefore, the idea of the proposed parameter estimation method is to find the estimators of $\alpha$ and $\beta$, which can make $y_{i}$ approximate the uniform distribution as much as possible. In other words, the estimators of $\alpha$ and $\beta$ can satisfy as much as possible that the mean and variance of $y_{i}$ are $1 / 2$ and $1 / 12$, respectively. Because the sample mean $\bar{y}=\sum_{i=1}^{n} y_{i} / n$ and sample variance $S_{y}^{2}=\sum_{i=1}^{n}\left(y_{i}-\bar{y}\right)^{2} /(n-1)$ are unbiased estimators of population mean and population variance, respectively, the proposed parameter estimators can be obtained by solving the following equations:

$$
\left\{\begin{array}{l}
\bar{y} \cong \frac{1}{2} \\
S_{y}^{2} \cong \frac{1}{12} .
\end{array}\right.
$$

Equation (15) can be rewritten as follows:

$$
\left\{\sum_{i=1}^{n} \exp \left[-\left(\frac{t_{i}}{\beta}\right)^{\alpha}\right] \cong \frac{n}{2}, \sum_{i=1}^{n}\left\{\exp \left[-\left(\frac{t_{i}}{\beta}\right)^{\alpha}\right]\right\}^{2} \cong \frac{4 n-1}{12}\right. \text {. }
$$

Therefore, the estimators of $\alpha$ and $\beta$ can be obtained from equation (16) and denoted as $\widehat{\alpha}_{C D F}$ and $\widehat{\beta}_{C D F}$, respectively. Since the proposed parameter estimation method is based on CDF, we name this method CDFM (cumulative distribution function method). Then, $\alpha$ and $\beta$ in equations (3) and (4) are replaced by $\widehat{\alpha}_{C D F}$ and $\widehat{\beta}_{C D F}$, respectively, so the RF and FRF based on CDFM can be obtained and expressed as

$$
\begin{aligned}
& \widehat{R}(t)=e^{-\left(t / \widehat{\beta}_{C D F}\right)^{\widehat{\alpha}_{C D F}}}, \quad t>0, \\
& \hat{\lambda}(t)=\frac{\widehat{\alpha}_{C D F}}{\widehat{\beta}_{C D F}}\left(\frac{t}{\widehat{\beta}_{C D F}}\right)^{\widehat{\alpha}_{C D F}-1}, \quad t>0 .
\end{aligned}
$$

Since the close-form solution of the proposed estimation is not available, the estimators can be obtained by using numerical optimization methods such as the quasi-Newton algorithm [27]. Figure 2 shows the flow chart of the parameter estimation process. When we obtain a sample data $T$, the estimators of the parameters, $\widehat{\alpha}_{C D F}$ and $\widehat{\beta}_{C D F}$, can be obtained according to the proposed parameter estimation method. Then, the goodness of fit test is used to test whether the data comes from the Weibull distribution with parameters $\widehat{\alpha}_{C D F}$ and $\widehat{\beta}_{C D F}$. Common goodness of fit tests include KolmogorovSmirnov test (K-S test) and Anderson-Darling test. When the test results show that the data does not follow the Weibull distribution, we must find the exact distribution of the data before inference. When the test results show that the data may come from the Weibull distribution, we can use equations (17) and (18) to estimate RF and FRF.

\section{Monte Carlo Simulation Study}

In this section, all simulation results are obtained by $\mathrm{R}$ software. The $\mathrm{R}$ codes can be obtained from the authors upon request. In this simulation study, we compare proposed estimation method CDFM with MLE, LM, PM, and MM. For convenience, we denoted the results estimated by these methods as $\widehat{\theta}_{C D F M}=\left(\widehat{\alpha}_{C D F M}, \widehat{\beta}_{C D F M}\right)$, $\widehat{\theta}_{M L E}=\left(\widehat{\alpha}_{M L E}, \widehat{\beta}_{M L E}\right), \quad \widehat{\theta}_{L M}=\left(\widehat{\alpha}_{L M}, \widehat{\beta}_{L M}\right), \widehat{\theta}_{P M}=\left(\widehat{\alpha}_{P M}\right.$, $\left.\widehat{\beta}_{P M}\right)$, and $\widehat{\theta}_{M M}=\left(\widehat{\alpha}_{M M}, \widehat{\beta}_{M M}\right)$, respectively. Considering the sample size $n=10,20,30,40,50,60,70$, and data set are generated from the $W D(\alpha, \beta)$, where $\alpha=1,2,4,6$ and $\beta=1,2$. Ten thousand iteration runs are used to evaluate the bias and MSEs of five estimation methods. 


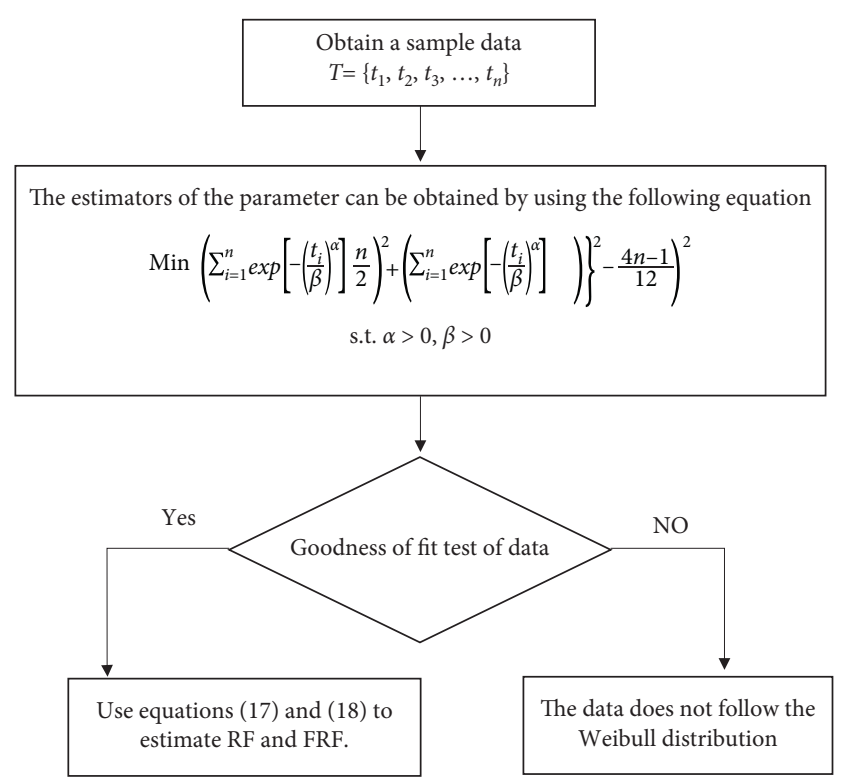

FIGURE 2: Flowchart of proposed parameter estimation.

The bias and MSE can be evaluated based on equations (19) and (20), respectively:

$$
\begin{aligned}
\text { bias } & =\frac{1}{10000}\left|\sum_{i=1}^{10000}\left(\widehat{\eta}_{i}-\eta\right)\right|, \\
\text { MSE } & =\sqrt{\frac{1}{10000} \sum_{i=1}^{10000}\left(\widehat{\eta}_{i}-\eta\right)^{2},}
\end{aligned}
$$

where $\eta$ can be $\alpha$ or $\beta$ and the subscript $i$ denotes the five estimation methods. All obtained biases and MSEs are reported in Tables 1 and 2. In view of Tables 1 and 2, the following results are found:

(1) With the increase of sample size, the performance of bias and MSE of all methods are getting better and better.

(2) For the bias of shape parameter $\alpha$, the performance of $\widehat{\alpha}_{C D F M}$ outperforms other methods in most cases, followed by $\widehat{\alpha}_{L M}$.

(3) For the MSE of $\alpha$, the performance of $\widehat{\alpha}_{L M}$ outperforms other methods in most cases, followed by $\widehat{\alpha}_{M L}$ and $\widehat{\alpha}_{C D F M}$.

(4) For the bias of scale parameter $\beta$, the performance of $\widehat{\beta}_{C D F M}$ outperforms other methods for $n=10$, except $\alpha=1$. And the performance of $\widehat{\beta}_{L M}$ outperforms other methods in most cases.

(5) For the MSE of $\beta$, the performance of $\widehat{\beta}_{L M}$ outperforms other methods, while the performance of $\widehat{\beta}_{M L M}$ is the worst.

(6) With the increase of the population shape parameter, the bias of $\alpha$ is larger and larger, and the bias of $\beta$ is smaller and smaller for all methods.

(7) When $\beta=1$, the performance of each estimation method is similar to that of $\beta=2$.
According to the above findings, the bias of $\widehat{\alpha}_{C D F M}$ outperforms other methods. Although the bias of $\widehat{\beta}_{C D F M}$ is worse than $\widehat{\beta}_{L M}$, the difference is not significant. Therefore, using the proposed estimation method for inference can get reliable results.

In addition, in order to compare the performance of the RF and FRF based on different parameter estimation methods, we consider that the sample size $n=10,20,30,40$, $50,60,70, \alpha=1,2,4,6, \beta=1$, and strength $t=2$. All the simulation results are shown in Figures 3 and 4. In view of Figures 3 and 4, the following results are found:

(1) The performance of biases of the RF and FRF estimated by CDFM method outperforms other methods in most cases.

(2) With the increase of $\alpha$ or sample size $n$, the performance of biases of each estimation method is better for RF and FRF.

(3) Among all estimation methods, PM method performs the worst for biases of RF and FRF.

(4) Among all estimation methods, PM method also performs the worst for MSEs of RF and FRF.

(5) With the increase of $\alpha$ or sample size $n$, the performance of MSEs of each estimation method is better for RF and FRF.

(6) Except PM method, the performance of MSEs of other estimation methods is very close for RF and FRF.

\section{Real Data Analysis}

5.1. Example 1. The tensile strength data of glass fiber, reported by Smith and Naylor [28] and further studied by Acitas et al. [3], Morais and Barreto-Souza [29], Alizadeh et al. [30], and Jones and Faddy [31], is used to illustrate the methodologies developed in this paper. In the article of Smith and Naylor [28], two experimental strength data sets of glass fiber of two lengths, $1.5 \mathrm{~cm}$ and $15 \mathrm{~cm}$, are provided, originally obtained by workers at the UK National Physical Laboratory. Unfortunately, the units of measurement are not given in the paper. In this example, the data of $1.5 \mathrm{~cm}$ length is selected for analysis. The strength data is shown in Table 3.

Two-parameter Weibull distribution is used to characterize the data in Table 3. Moreover, the CDFM, MLE, LM, $\mathrm{PM}$, and MM estimation methods are used to obtain the estimates of the Weibull distribution parameters. All the estimation results are reported in Table 4 . The estimators of LM are consistent with those of Acitas et al. [3]. The $p$ value of the K-S test in Table 4 indicates that the Weibull distribution can well fit this data set and we found the CDFM estimation method is the best estimation method to obtain the estimates of the Weibull distribution parameters. In addition, Figure 5 presents the histogram of sample and the fitted PDFs of the Weibull distributions by using the parameter estimation results in Table 4. Figure 6 presents empirical distribution function of sample and the fitted CDFs of the Weibull distributions by using the parameter estimation results in Table 4. As shown in Figure 5, the PDF 
TABLE 1: The bias and MSE of five estimation methods for $\beta=1, \alpha=1,2,4,6$.

\begin{tabular}{|c|c|c|c|c|c|c|c|c|c|c|}
\hline \multicolumn{3}{|c|}{$\beta=1$} & \multicolumn{2}{|c|}{$\alpha=1$} & \multicolumn{2}{|c|}{$\alpha=2$} & \multicolumn{2}{|c|}{$\alpha=4$} & \multicolumn{2}{|c|}{$\alpha=6$} \\
\hline $\mathrm{n}$ & \multicolumn{2}{|c|}{ Method } & $\widehat{\alpha}_{i}$ & $\widehat{\beta}_{i}$ & $\widehat{\alpha}_{i}$ & $\hat{\beta}_{i}$ & $\widehat{\alpha}_{i}$ & $\hat{\beta}_{i}$ & $\widehat{\alpha}_{i}$ & $\widehat{\beta}_{i}$ \\
\hline \multirow[t]{10}{*}{10} & \multirow{2}{*}{ CDFM } & Bias & 0.053 & 0.042 & 0.097 & 0.004 & 0.240 & 0.001 & 0.313 & 0.002 \\
\hline & & MSE & 0.129 & 0.123 & 0.495 & 0.029 & 2.148 & 0.007 & 4.564 & 0.003 \\
\hline & \multirow[t]{2}{*}{ ML } & Bias & 0.169 & 0.016 & 0.327 & 0.007 & 0.703 & 0.006 & 1.020 & 0.006 \\
\hline & & MSE & 0.152 & 0.112 & 0.589 & 0.027 & 2.534 & 0.007 & 5.561 & 0.003 \\
\hline & \multirow[t]{2}{*}{ LM } & Bias & 0.056 & 0.029 & 0.103 & 0.011 & 0.294 & 0.003 & 0.445 & 0.002 \\
\hline & & MSE & 0.110 & 0.112 & 0.424 & 0.028 & 1.939 & 0.007 & 4.367 & 0.003 \\
\hline & \multirow[t]{2}{*}{$\mathrm{PM}$} & Bias & 0.507 & 0.016 & 0.981 & 0.015 & 1.988 & 0.012 & 2.842 & 0.009 \\
\hline & & MSE & 1.344 & 0.153 & 4.762 & 0.038 & 20.94 & 0.009 & 41.75 & 0.004 \\
\hline & \multirow[t]{2}{*}{ MM } & Bias & 0.167 & 0.020 & 0.182 & 0.008 & 0.420 & 0.004 & 0.660 & 0.003 \\
\hline & & MSE & 0.131 & 0.113 & 0.441 & 0.028 & 2.155 & 0.007 & 5.066 & 0.003 \\
\hline \multirow[t]{10}{*}{20} & CDFM & Bias & 0.029 & 0.021 & 0.045 & 0.002 & 0.094 & 0.001 & 0.137 & 0.001 \\
\hline & & MSE & 0.051 & 0.061 & 0.192 & 0.015 & 0.816 & 0.004 & 1.851 & 0.002 \\
\hline & ML & Bias & 0.080 & 0.010 & 0.153 & 0.004 & 0.310 & 0.002 & 0.441 & 0.003 \\
\hline & & MSE & 0.050 & 0.057 & 0.187 & 0.014 & 0.794 & 0.003 & 1.761 & 0.002 \\
\hline & LM & Bias & 0.029 & 0.012 & 0.048 & 0.006 & 0.121 & 0.000 & 0.185 & 0.001 \\
\hline & & MSE & 0.045 & 0.057 & 0.156 & 0.014 & 0.717 & 0.003 & 1.662 & 0.002 \\
\hline & $\mathrm{PM}$ & Bias & 0.246 & 0.006 & 0.457 & 0.008 & 0.896 & 0.004 & 1.411 & 0.005 \\
\hline & & MSE & 0.361 & 0.085 & 1.373 & 0.021 & 5.238 & 0.005 & 12.95 & 0.002 \\
\hline & MM & Bias & 0.091 & 0.012 & 0.088 & 0.005 & 0.176 & 0.001 & 0.278 & 0.002 \\
\hline & & MSE & 0.055 & 0.058 & 0.156 & 0.014 & 0.747 & 0.003 & 1.814 & 0.002 \\
\hline 30 & CDFM & Bias & 0.016 & 0.015 & 0.026 & 0.001 & 0.069 & 0.001 & 0.068 & 0.000 \\
\hline & & MSE & 0.031 & 0.040 & 0.122 & 0.010 & 0.498 & 0.002 & 1.121 & 0.001 \\
\hline & ML & Bias & 0.050 & 0.008 & 0.096 & 0.003 & 0.206 & 0.001 & 0.279 & 0.002 \\
\hline & & MSE & 0.028 & 0.038 & 0.110 & 0.009 & 0.441 & 0.002 & 0.986 & 0.001 \\
\hline & LM & Bias & 0.017 & 0.007 & 0.027 & 0.004 & 0.087 & 0.000 & 0.109 & 0.000 \\
\hline & & MSE & 0.027 & 0.038 & 0.100 & 0.009 & 0.430 & 0.002 & 1.003 & 0.001 \\
\hline & PM & Bias & 0.141 & 0.006 & 0.271 & 0.006 & 0.570 & 0.003 & 0.823 & 0.003 \\
\hline & & MSE & 0.166 & 0.055 & 0.625 & 0.014 & 2.635 & 0.003 & 5.884 & 0.002 \\
\hline & MM & Bias & 0.062 & 0.009 & 0.054 & 0.004 & 0.123 & 0.000 & 0.172 & 0.001 \\
\hline & & MSE & 0.034 & 0.039 & 0.099 & 0.009 & 0.437 & 0.002 & 1.075 & 0.001 \\
\hline 40 & CDFM & Bias & 0.011 & 0.015 & 0.031 & 0.001 & 0.092 & 0.001 & 0.162 & 0.002 \\
\hline & & MSE & 0.023 & 0.031 & 0.095 & 0.007 & 0.377 & 0.002 & 0.857 & 0.001 \\
\hline & ML & Bias & 0.041 & 0.007 & 0.087 & 0.001 & 0.188 & 0.002 & 0.286 & 0.002 \\
\hline & & MSE & 0.021 & 0.029 & 0.084 & 0.007 & 0.350 & 0.002 & 0.747 & 0.001 \\
\hline & LM & Bias & 0.018 & 0.003 & 0.033 & 0.002 & 0.103 & 0.001 & 0.178 & 0.002 \\
\hline & & MSE & 0.019 & 0.029 & 0.077 & 0.007 & 0.328 & 0.002 & 0.763 & 0.001 \\
\hline & $\mathrm{PM}$ & Bias & 0.095 & 0.010 & 0.227 & 0.004 & 0.442 & 0.004 & 0.748 & 0.001 \\
\hline & & MSE & 0.100 & 0.044 & 0.524 & 0.011 & 1.692 & 0.003 & 3.805 & 0.001 \\
\hline & MM & Bias & 0.056 & 0.010 & 0.054 & 0.002 & 0.128 & 0.001 & 0.222 & 0.002 \\
\hline & & MSE & 0.026 & 0.030 & 0.077 & 0.007 & 0.332 & 0.002 & 0.813 & 0.001 \\
\hline 50 & CDFM & Bias & 0.008 & 0.007 & 0.020 & 0.001 & 0.035 & 0.000 & 0.048 & 0.001 \\
\hline & & MSE & 0.017 & 0.024 & 0.070 & 0.006 & 0.288 & 0.001 & 0.622 & 0.001 \\
\hline & ML & Bias & 0.028 & 0.003 & 0.060 & 0.000 & 0.118 & 0.001 & 0.168 & 0.001 \\
\hline & & MSE & 0.015 & 0.022 & 0.059 & 0.006 & 0.240 & 0.001 & 0.526 & 0.001 \\
\hline & LM & Bias & 0.009 & 0.006 & 0.020 & 0.001 & 0.045 & 0.001 & 0.070 & 0.000 \\
\hline & & MSE & 0.015 & 0.023 & 0.056 & 0.006 & 0.245 & 0.001 & 0.557 & 0.001 \\
\hline & PM & Bias & 0.081 & 0.001 & 0.167 & 0.003 & 0.329 & 0.002 & 0.485 & 0.002 \\
\hline & & MSE & 0.079 & 0.034 & 0.313 & 0.009 & 1.237 & 0.002 & 2.718 & 0.001 \\
\hline & MM & Bias & 0.038 & 0.004 & 0.035 & 0.001 & 0.065 & 0.001 & 0.106 & 0.001 \\
\hline & & MSE & 0.019 & 0.023 & 0.055 & 0.006 & 0.244 & 0.001 & 0.591 & 0.001 \\
\hline 60 & CDFM & Bias & 0.010 & 0.015 & 0.008 & 0.000 & 0.032 & 0.001 & 0.029 & 0.000 \\
\hline & & MSE & 0.014 & 0.019 & 0.055 & 0.005 & 0.225 & 0.001 & 0.496 & 0.001 \\
\hline & ML & Bias & 0.028 & 0.009 & 0.040 & 0.002 & 0.100 & 0.002 & 0.125 & 0.000 \\
\hline & & MSE & 0.012 & 0.018 & 0.043 & 0.005 & 0.189 & 0.001 & 0.402 & 0.001 \\
\hline & LM & Bias & 0.015 & 0.003 & 0.008 & 0.003 & 0.043 & 0.001 & 0.045 & 0.001 \\
\hline & & MSE & 0.012 & 0.018 & 0.043 & 0.005 & 0.196 & 0.001 & 0.433 & 0.001 \\
\hline & PM & Bias & 0.065 & 0.012 & 0.124 & 0.002 & 0.237 & 0.003 & 0.416 & -0.002 \\
\hline & & MSE & 0.055 & 0.029 & 0.254 & 0.007 & 0.907 & 0.002 & 2.044 & 0.001 \\
\hline & MM & Bias & 0.040 & 0.012 & 0.020 & 0.002 & 0.061 & 0.002 & 0.075 & 0.000 \\
\hline & & MSE & 0.017 & 0.019 & 0.041 & 0.005 & 0.196 & 0.001 & 0.453 & 0.001 \\
\hline
\end{tabular}


TABle 1: Continued.

\begin{tabular}{|c|c|c|c|c|c|c|c|c|c|c|}
\hline \multicolumn{3}{|c|}{$\beta=1$} & \multicolumn{2}{|c|}{$\alpha=1$} & \multicolumn{2}{|c|}{$\alpha=2$} & \multicolumn{2}{|c|}{$\alpha=4$} & \multicolumn{2}{|c|}{$\alpha=6$} \\
\hline $\mathrm{n}$ & \multicolumn{2}{|c|}{ Method } & $\widehat{\alpha}_{i}$ & $\widehat{\beta}_{i}$ & $\widehat{\alpha}_{i}$ & $\widehat{\beta}_{i}$ & $\widehat{\alpha}_{i}$ & $\widehat{\beta}_{i}$ & $\widehat{\alpha}_{i}$ & $\widehat{\beta}_{i}$ \\
\hline \multirow[t]{10}{*}{70} & CDFM & Bias & 0.006 & 0.008 & 0.010 & 0.000 & 0.052 & 0.002 & 0.046 & 0.000 \\
\hline & & MSE & 0.011 & 0.017 & 0.049 & 0.004 & 0.217 & 0.001 & 0.452 & 0.000 \\
\hline & ML & Bias & 0.021 & 0.004 & 0.035 & 0.001 & 0.108 & 0.002 & 0.134 & 0.001 \\
\hline & & MSE & 0.009 & 0.016 & 0.039 & 0.004 & 0.180 & 0.001 & 0.374 & 0.000 \\
\hline & LM & Bias & 0.007 & 0.002 & 0.008 & 0.002 & 0.058 & 0.002 & 0.062 & 0.000 \\
\hline & & MSE & 0.010 & 0.016 & 0.039 & 0.004 & 0.184 & 0.001 & 0.397 & 0.000 \\
\hline & $\mathrm{PM}$ & Bias & 0.058 & 0.003 & 0.118 & 0.004 & 0.233 & 0.003 & 0.363 & 0.002 \\
\hline & & MSE & 0.048 & 0.026 & 0.206 & 0.006 & 0.787 & 0.001 & 1.807 & 0.001 \\
\hline & MM & Bias & 0.028 & 0.005 & 0.017 & 0.002 & 0.072 & 0.002 & 0.088 & 0.000 \\
\hline & & MSE & 0.014 & 0.017 & 0.038 & 0.004 & 0.183 & 0.001 & 0.415 & 0.000 \\
\hline
\end{tabular}

TABle 2: The bias and MSE of five estimation methods for $\beta=2, \alpha=1,2,4,6$.

\begin{tabular}{|c|c|c|c|c|c|c|c|c|c|c|}
\hline \multicolumn{3}{|c|}{$\beta=2$} & \multicolumn{2}{|c|}{$\alpha=1$} & \multicolumn{2}{|c|}{$\alpha=2$} & \multicolumn{2}{|c|}{$\alpha=4$} & \multicolumn{2}{|c|}{$\alpha=6$} \\
\hline $\mathrm{n}$ & \multicolumn{2}{|c|}{ Method } & $\widehat{\alpha}_{i}$ & $\widehat{\beta}_{i}$ & $\widehat{\alpha}_{i}$ & $\widehat{\beta}_{i}$ & $\widehat{\alpha}_{i}$ & $\widehat{\beta}_{i}$ & $\widehat{\alpha}_{i}$ & $\widehat{\beta}_{i}$ \\
\hline \multirow[t]{10}{*}{10} & \multirow[t]{2}{*}{ CDFM } & Bias & 0.046 & 0.079 & 0.107 & 0.014 & 0.203 & 0.003 & 0.285 & 0.004 \\
\hline & & MSE & 0.131 & 0.482 & 0.507 & 0.116 & 2.100 & 0.029 & 4.535 & 0.013 \\
\hline & \multirow[t]{2}{*}{ ML } & Bias & 0.169 & 0.036 & 0.341 & 0.009 & 0.666 & 0.014 & 0.980 & 0.011 \\
\hline & & MSE & 0.154 & 0.461 & 0.611 & 0.109 & 2.411 & 0.028 & 5.371 & 0.012 \\
\hline & \multirow[t]{2}{*}{ LM } & Bias & 0.055 & 0.055 & 0.114 & 0.016 & 0.264 & 0.006 & 0.414 & 0.004 \\
\hline & & MSE & 0.112 & 0.460 & 0.435 & 0.111 & 1.890 & 0.028 & 4.362 & 0.012 \\
\hline & \multirow[t]{2}{*}{ PM } & Bias & 0.506 & 0.037 & 1.004 & 0.025 & 2.001 & 0.026 & 2.825 & 0.020 \\
\hline & & MSE & 1.310 & 0.635 & 5.146 & 0.151 & 22.20 & 0.039 & 46.90 & 0.017 \\
\hline & \multirow[t]{2}{*}{ MM } & Bias & 0.167 & 0.042 & 0.194 & 0.012 & 0.387 & 0.009 & 0.629 & 0.007 \\
\hline & & MSE & 0.134 & 0.461 & 0.454 & 0.110 & 2.072 & 0.028 & 5.072 & 0.012 \\
\hline \multirow[t]{10}{*}{20} & \multirow[t]{2}{*}{ CDFM } & Bias & 0.022 & 0.033 & 0.042 & 0.006 & 0.107 & 0.001 & 0.131 & 0.002 \\
\hline & & MSE & 0.050 & 0.244 & 0.196 & 0.057 & 0.818 & 0.014 & 1.786 & 0.007 \\
\hline & \multirow[t]{2}{*}{ ML } & Bias & 0.074 & 0.009 & 0.149 & 0.006 & 0.312 & 0.006 & 0.454 & 0.005 \\
\hline & & MSE & 0.048 & 0.228 & 0.191 & 0.054 & 0.804 & 0.014 & 1.754 & 0.006 \\
\hline & \multirow[t]{2}{*}{ LM } & Bias & 0.025 & 0.035 & 0.044 & 0.009 & 0.129 & 0.002 & 0.188 & 0.002 \\
\hline & & MSE & 0.043 & 0.230 & 0.161 & 0.055 & 0.722 & 0.014 & 1.648 & 0.006 \\
\hline & \multirow[t]{2}{*}{ PM } & Bias & 0.232 & 0.011 & 0.447 & 0.013 & 0.929 & 0.013 & 1.357 & 0.009 \\
\hline & & MSE & 0.351 & 0.342 & 1.320 & 0.081 & 5.424 & 0.021 & 12.00 & 0.009 \\
\hline & \multirow[t]{2}{*}{ MM } & Bias & 0.088 & 0.014 & 0.084 & 0.007 & 0.183 & 0.004 & 0.285 & 0.003 \\
\hline & & MSE & 0.053 & 0.232 & 0.160 & 0.055 & 0.751 & 0.014 & 1.812 & 0.006 \\
\hline \multirow[t]{10}{*}{30} & \multirow[t]{2}{*}{ CDFM } & Bias & 0.015 & 0.026 & 0.031 & 0.005 & 0.055 & 0.000 & 0.096 & 0.000 \\
\hline & & MSE & 0.030 & 0.160 & 0.123 & 0.040 & 0.485 & 0.010 & 1.126 & 0.004 \\
\hline & \multirow[t]{2}{*}{ ML } & Bias & 0.049 & 0.011 & 0.099 & 0.002 & 0.195 & 0.004 & 0.298 & 0.002 \\
\hline & & MSE & 0.028 & 0.149 & 0.110 & 0.038 & 0.434 & 0.009 & 1.005 & 0.004 \\
\hline & \multirow[t]{2}{*}{ LM } & Bias & 0.016 & 0.019 & 0.031 & 0.004 & 0.071 & 0.002 & 0.126 & 0.000 \\
\hline & & MSE & 0.027 & 0.151 & 0.100 & 0.038 & 0.414 & 0.009 & 1.004 & 0.004 \\
\hline & \multirow[t]{2}{*}{$\mathrm{PM}$} & Bias & 0.138 & 0.010 & 0.282 & 0.008 & 0.561 & 0.008 & 0.887 & 0.005 \\
\hline & & MSE & 0.159 & 0.221 & 0.640 & 0.056 & 2.712 & 0.014 & 6.070 & 0.006 \\
\hline & MM & Bias & 0.062 & 0.015 & 0.056 & 0.003 & 0.105 & 0.003 & 0.185 & 0.001 \\
\hline & & MSE & 0.034 & 0.154 & 0.099 & 0.038 & 0.419 & 0.009 & 1.077 & 0.004 \\
\hline 40 & CDFM & Bias & 0.014 & 0.004 & 0.019 & 0.003 & 0.031 & 0.006 & 0.058 & 0.000 \\
\hline & & MSE & 0.020 & 0.121 & 0.086 & 0.027 & 0.318 & 0.007 & 0.827 & 0.003 \\
\hline & ML & Bias & 0.040 & 0.012 & 0.067 & 0.002 & 0.137 & 0.002 & 0.211 & 0.002 \\
\hline & & MSE & 0.020 & 0.114 & 0.073 & 0.026 & 0.267 & 0.007 & 0.704 & 0.003 \\
\hline & LM & Bias & 0.012 & 0.036 & 0.019 & 0.003 & 0.041 & 0.004 & 0.091 & 0.000 \\
\hline & & MSE & 0.019 & 0.117 & 0.070 & 0.026 & 0.267 & 0.007 & 0.754 & 0.003 \\
\hline & PM & Bias & 0.109 & 0.024 & 0.185 & 0.008 & 0.412 & 0.001 & 0.586 & 0.004 \\
\hline & & MSE & 0.095 & 0.172 & 0.375 & 0.040 & 1.577 & 0.010 & 3.699 & 0.005 \\
\hline & MM & Bias & 0.045 & 0.014 & 0.038 & 0.003 & 0.066 & 0.004 & 0.135 & 0.001 \\
\hline & & MSE & 0.025 & 0.118 & 0.069 & 0.026 & 0.265 & 0.007 & 0.800 & 0.003 \\
\hline
\end{tabular}


TABLE 2: Continued.

\begin{tabular}{|c|c|c|c|c|c|c|c|c|c|c|}
\hline \multicolumn{3}{|c|}{$\beta=2$} & \multicolumn{2}{|c|}{$\alpha=1$} & \multicolumn{2}{|c|}{$\alpha=2$} & \multicolumn{2}{|c|}{$\alpha=4$} & \multicolumn{2}{|c|}{$\alpha=6$} \\
\hline $\mathrm{n}$ & \multicolumn{2}{|c|}{ Method } & $\widehat{\alpha}_{i}$ & $\widehat{\beta}_{i}$ & $\widehat{\alpha}_{i}$ & $\hat{\beta}_{i}$ & $\widehat{\alpha}_{i}$ & $\hat{\beta}_{i}$ & $\widehat{\alpha}_{i}$ & $\widehat{\beta}_{i}$ \\
\hline \multirow[t]{10}{*}{50} & \multirow[t]{2}{*}{ CDFM } & Bias & 0.012 & 0.019 & 0.017 & 0.004 & 0.035 & 0.001 & 0.062 & 0.001 \\
\hline & & MSE & 0.018 & 0.097 & 0.071 & 0.023 & 0.279 & 0.006 & 0.619 & 0.003 \\
\hline & \multirow[t]{2}{*}{ ML } & Bias & 0.031 & 0.010 & 0.058 & 0.001 & 0.116 & 0.003 & 0.175 & 0.002 \\
\hline & & MSE & 0.015 & 0.091 & 0.060 & 0.022 & 0.234 & 0.006 & 0.528 & 0.002 \\
\hline & \multirow[t]{2}{*}{ LM } & Bias & 0.011 & 0.008 & 0.017 & 0.002 & 0.045 & 0.002 & 0.085 & 0.000 \\
\hline & & MSE & 0.015 & 0.092 & 0.057 & 0.022 & 0.238 & 0.006 & 0.559 & 0.002 \\
\hline & \multirow[t]{2}{*}{$\mathrm{PM}$} & Bias & 0.086 & 0.006 & 0.160 & 0.005 & 0.314 & 0.006 & 0.491 & 0.005 \\
\hline & & MSE & 0.076 & 0.137 & 0.308 & 0.033 & 1.199 & 0.009 & 2.727 & 0.004 \\
\hline & \multirow[t]{2}{*}{$\mathrm{MM}$} & Bias & 0.040 & 0.012 & 0.033 & 0.001 & 0.065 & 0.003 & 0.123 & 0.001 \\
\hline & & MSE & 0.020 & 0.095 & 0.056 & 0.022 & 0.238 & 0.006 & 0.596 & 0.002 \\
\hline \multirow[t]{10}{*}{60} & \multirow[t]{2}{*}{ CDFM } & Bias & 0.011 & 0.013 & 0.012 & 0.005 & 0.026 & 0.003 & 0.044 & 0.002 \\
\hline & & MSE & 0.015 & 0.076 & 0.057 & 0.019 & 0.228 & 0.005 & 0.546 & 0.002 \\
\hline & \multirow[t]{2}{*}{ ML } & Bias & 0.025 & 0.005 & 0.052 & 0.001 & 0.093 & 0.005 & 0.146 & 0.003 \\
\hline & & MSE & 0.012 & 0.069 & 0.046 & 0.018 & 0.189 & 0.005 & 0.453 & 0.002 \\
\hline & \multirow[t]{2}{*}{ LM } & Bias & 0.011 & 0.009 & 0.016 & 0.000 & 0.036 & 0.004 & 0.061 & 0.001 \\
\hline & & MSE & 0.012 & 0.071 & 0.045 & 0.018 & 0.197 & 0.005 & 0.473 & 0.002 \\
\hline & \multirow[t]{2}{*}{$\mathrm{PM}$} & Bias & 0.075 & 0.009 & 0.126 & 0.000 & 0.268 & 0.007 & 0.420 & 0.003 \\
\hline & & MSE & 0.062 & 0.114 & 0.237 & 0.028 & 0.966 & 0.007 & 2.266 & 0.003 \\
\hline & \multirow[t]{2}{*}{ MM } & Bias & 0.035 & 0.008 & 0.030 & 0.000 & 0.053 & 0.004 & 0.091 & 0.002 \\
\hline & & MSE & 0.016 & 0.073 & 0.044 & 0.018 & 0.197 & 0.005 & 0.493 & 0.002 \\
\hline \multirow[t]{10}{*}{70} & \multirow[t]{2}{*}{ CDFM } & Bias & 0.006 & 0.013 & 0.006 & 0.004 & 0.024 & 0.004 & 0.066 & 0.002 \\
\hline & & MSE & 0.013 & 0.068 & 0.046 & 0.015 & 0.200 & 0.004 & 0.461 & 0.002 \\
\hline & \multirow[t]{2}{*}{ ML } & Bias & 0.021 & 0.005 & 0.035 & 0.001 & 0.078 & 0.005 & 0.146 & 0.000 \\
\hline & & MSE & 0.010 & 0.064 & 0.037 & 0.014 & 0.155 & 0.004 & 0.389 & 0.002 \\
\hline & \multirow[t]{2}{*}{ LM } & Bias & 0.009 & 0.007 & 0.006 & 0.000 & 0.036 & 0.004 & 0.078 & 0.002 \\
\hline & & MSE & 0.011 & 0.064 & 0.036 & 0.014 & 0.170 & 0.004 & 0.417 & 0.002 \\
\hline & \multirow[t]{2}{*}{$\mathrm{PM}$} & Bias & 0.059 & 0.009 & 0.109 & 0.004 & 0.194 & 0.009 & 0.324 & 0.000 \\
\hline & & MSE & 0.050 & 0.097 & 0.186 & 0.022 & 0.737 & 0.006 & 1.515 & 0.003 \\
\hline & \multirow[t]{2}{*}{ MM } & Bias & 0.030 & 0.008 & 0.016 & 0.000 & 0.051 & 0.004 & 0.100 & 0.001 \\
\hline & & MSE & 0.014 & 0.067 & 0.036 & 0.014 & 0.169 & 0.004 & 0.441 & 0.002 \\
\hline
\end{tabular}

corresponding to CDFM is closest to the sample histogram, which also shows that the estimation result of CDFM is more suitable for this data. From Figure 6, we can also see that the curve corresponding to CDFM is closest to the empirical distribution function of the sample. The results in Figure 6 also show that the CDFM is more suitable for this data.

Suppose we want to estimate the reliability and failure rate of glass fiber, we can substitute equations (17) and (18) according to the parameter estimator results in Table 4 , and the results are shown in Figure 7. From Figure 7, the results show that when $t<1.6$, the RF based on CDFM is higher than other methods except PM method; when $t>1.6$, the RF based on CDFM is lower than other methods except PM method. In addition, the FRF based on CDFM is higher than other methods except PM method.

5.2. Example 2. In this example, the data of $15 \mathrm{~cm}$ length reported by Smith and Naylor [28] is selected for analysis. The strength data is shown in Table 5. Two-parameter Weibull distribution is also used to characterize the data in Table 5. Moreover, the CDFM, MLE, LM, PM, and MM estimation methods are used to obtain the estimates of the Weibull distribution parameters. All the estimation results are reported in Table 6 . The $p$ value of the K-S test in Table 6 indicates that the Weibull distribution can well fit this data set and we found the CDFM estimation method is the best estimation method to obtain the estimates of the Weibull distribution parameters. In addition, Figure 8 presents the histogram of sample and the fitted PDFs of the Weibull distributions by using the parameter estimation results in Table 6. Figure 9 presents empirical distribution function of sample and the fitted CDFs of the Weibull distributions by using the parameter estimation results in Table 6 . The results in Figures 8 and 9 show that the fitting performance of these estimation methods for this sample is similar.

Suppose we want to estimate the reliability and failure rate of glass fiber, we can substitute equations (17) and (18) according to the parameter estimator results in Table 6 , and the results are shown in Figure 10. It can be seen from Figure 10 that the RF and FRF results estimated by each method are almost the same, because the parameter estimator results of this data set for each estimation method are almost the same. 

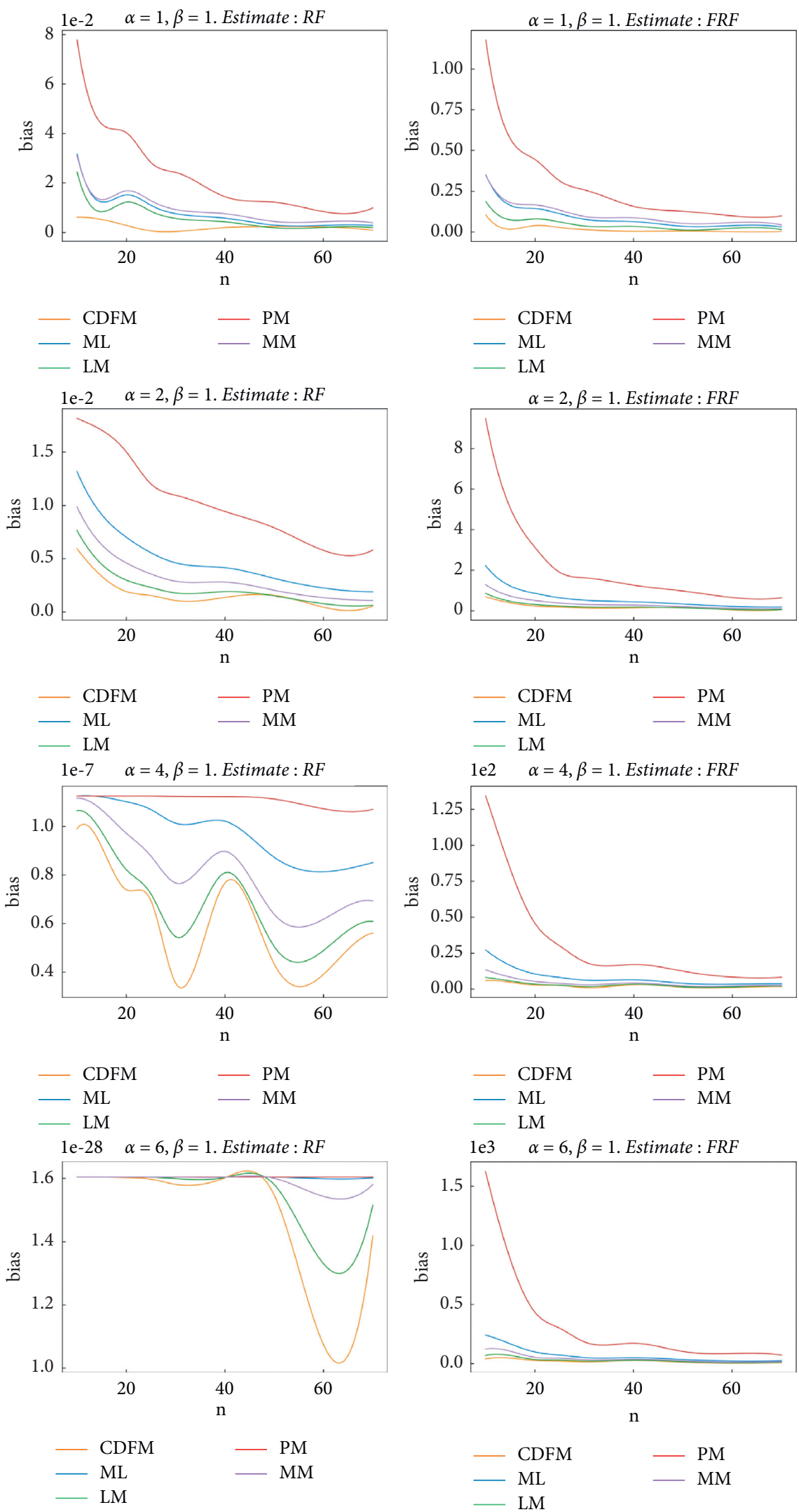

FIgURE 3: Comparison of biases of the RF and FRF based on CDFM and other four different parameter estimation methods (for $\beta=1$, $\alpha=1,2,4,6$ ). 

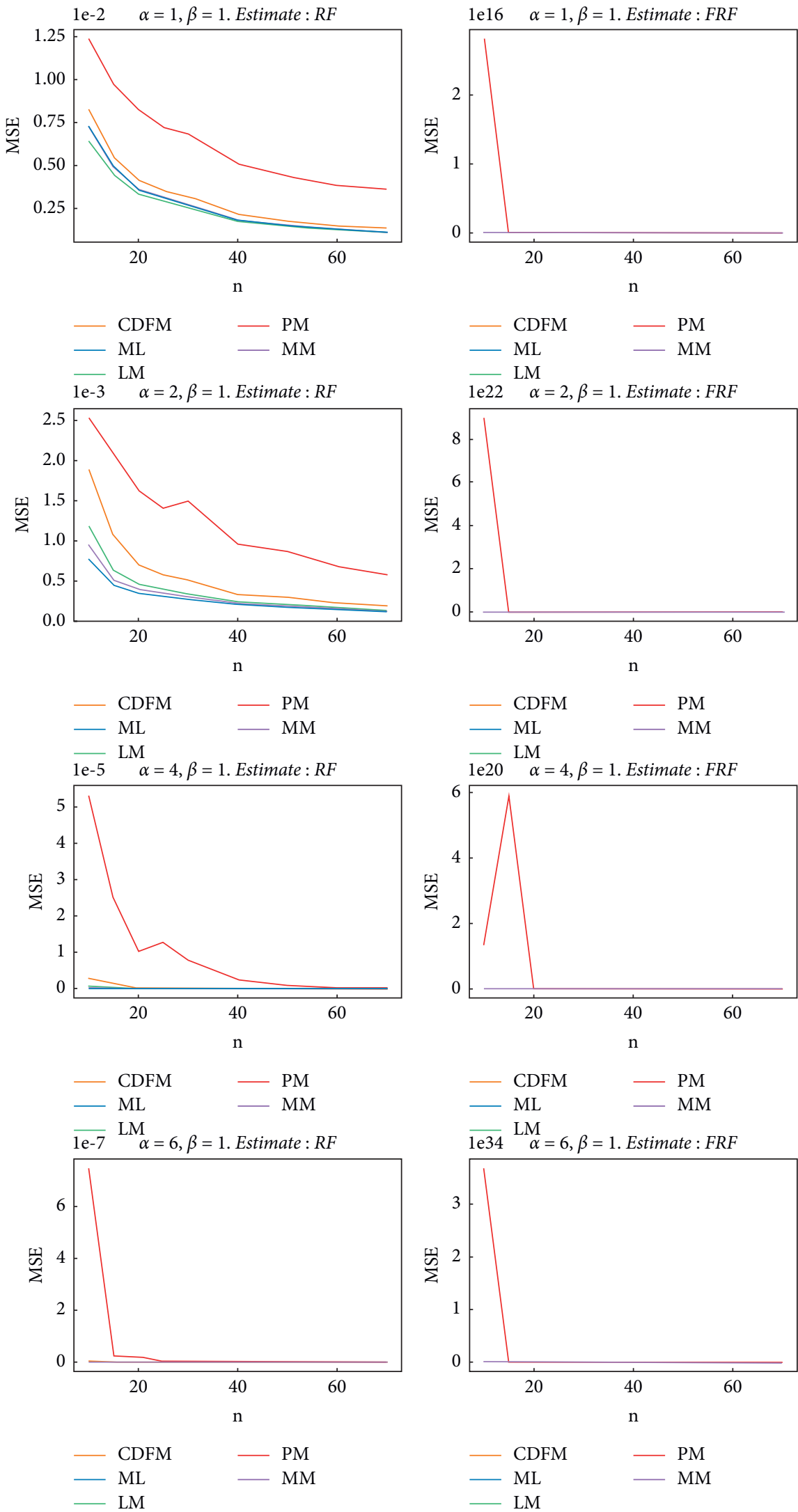

FIgURE 4: Comparison of MSEs of the RF and FRF based on CDFM and other four different parameter estimation methods (for $\beta=1$, $\alpha=1,2,4,6)$. 
TABle 3: Sample data set-1 of glass fiber strength $(1.5 \mathrm{~cm})$.

\begin{tabular}{|c|c|c|c|c|c|c|c|c|c|c|c|c|c|}
\hline 0.55 & 0.93 & 1.25 & 1.36 & 1.49 & 1.52 & 1.58 & 1.61 & 1.64 & 1.68 & 1.73 & 1.81 & 2.00 & 0.74 \\
\hline 1.04 & 1.27 & 1.39 & 1.49 & 1.53 & 1.59 & 1.61 & 1.66 & 1.68 & 1.76 & 1.82 & 2.01 & 0.77 & 1.11 \\
\hline 1.28 & 1.42 & 1.50 & 1.54 & 1.60 & 1.62 & 1.66 & 1.69 & 1.76 & 1.84 & 2.24 & 0.81 & 1.13 & 1.29 \\
\hline 1.48 & 1.50 & 1.55 & 1.61 & 1.62 & 1.66 & 1.70 & 1.77 & 1.84 & 0.84 & 1.24 & 1.30 & 1.48 & 1.51 \\
\hline 1.55 & 1.61 & 1.63 & 1.67 & 1.70 & 1.78 & 1.89 & & & & & & & \\
\hline
\end{tabular}

TABle 4: Estimate of the parameters and the $P$ value of K-S test for simple data set- 1.

\begin{tabular}{lccc}
\hline & Estimate of $\alpha$ & Estimate of $\beta$ & $P$ value of K-S test \\
\hline CDFM & 6.6381 & 1.6390 & 0.3980 \\
ML & 5.7807 & 1.6281 & 0.1001 \\
LM & 5.6573 & 1.6296 & 0.0863 \\
PM & 10.3026 & 1.6319 & 0.1254 \\
MM & 5.3554 & 1.6347 & 0.0802 \\
\hline
\end{tabular}

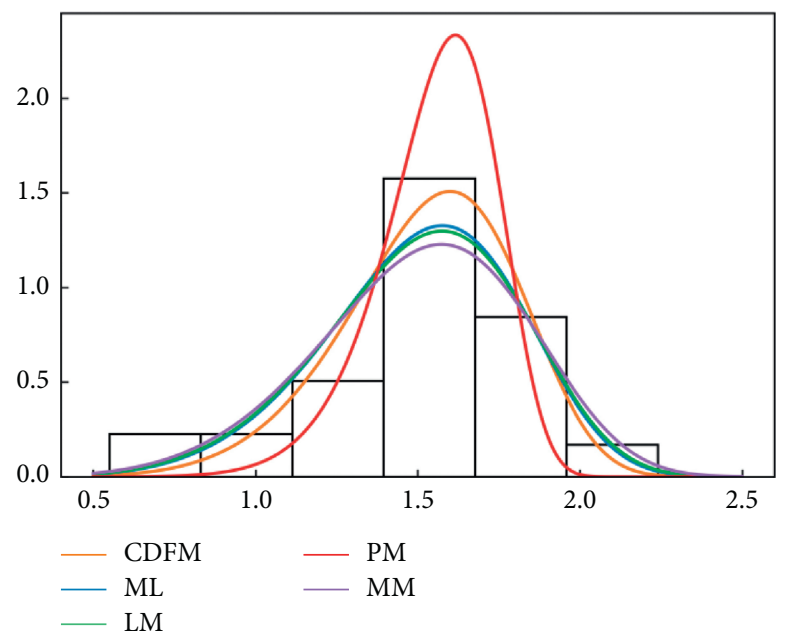

FIgURE 5: The histogram and the fitted PDFs of the Weibull distributions for sample data set-1.

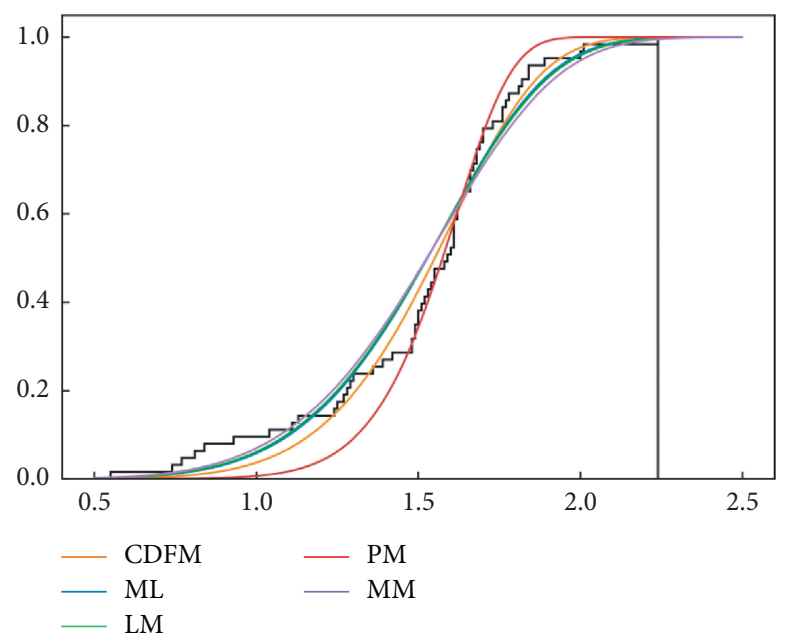

FIgURE 6: Empirical distribution function and the fitted CDFs of the Weibull distributions for sample data set-1. 

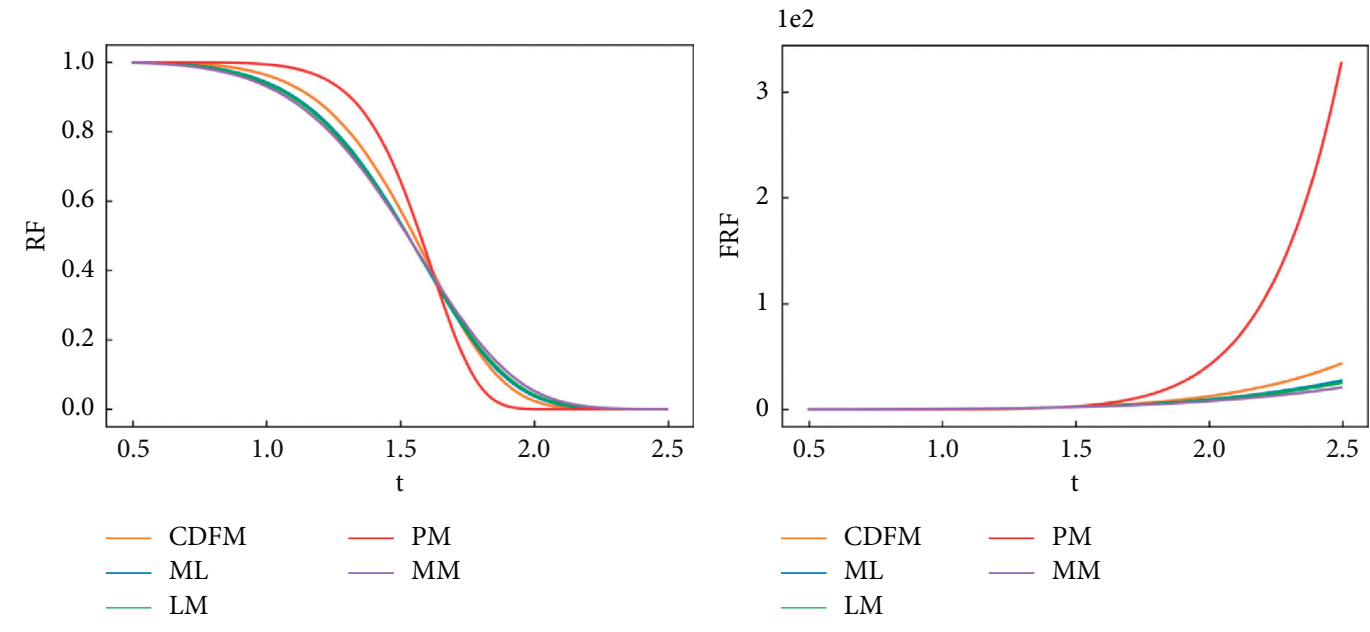

FIgURE 7: The RF and FRF based on different parameter estimation methods for sample data set-1.

TABle 5: Sample data set-2 of glass fiber strength $(15 \mathrm{~cm})$.

\begin{tabular}{|c|c|c|c|c|c|c|c|c|c|c|c|c|c|}
\hline 0.37 & 0.40 & 0.70 & 0.75 & 0.80 & 0.81 & 0.83 & 0.86 & 0.92 & 0.92 & 0.94 & 0.95 & 0.98 & 1.03 \\
\hline 1.06 & 1.06 & 1.08 & 1.09 & 1.10 & 1.10 & 1.13 & 1.14 & 1.15 & 1.17 & 1.20 & 1.20 & 1.21 & 1.22 \\
\hline 1.25 & 1.28 & 1.28 & 1.29 & 1.29 & 1.30 & 1.35 & 1.35 & 1.37 & 1.37 & 1.38 & 1.40 & 1.40 & 1.42 \\
\hline 1.43 & 1.51 & 1.53 & 1.61 & & & & & & & & & & \\
\hline
\end{tabular}

TABle 6: Estimate of the parameters and the $P$ value of K-S test for sample data set- 2 .

\begin{tabular}{lccc}
\hline & Estimate of $\alpha$ & Estimate of $\beta$ & $P$ value of K-S test \\
\hline CDFM & 5.0562 & 1.2432 & 0.9792 \\
ML & 5.1473 & 1.2297 & 0.9302 \\
LM & 4.8265 & 1.2332 & 0.9354 \\
PM & 5.6034 & 1.2634 & 0.9183 \\
MM & 4.7472 & 1.2344 & 0.9011 \\
\hline
\end{tabular}

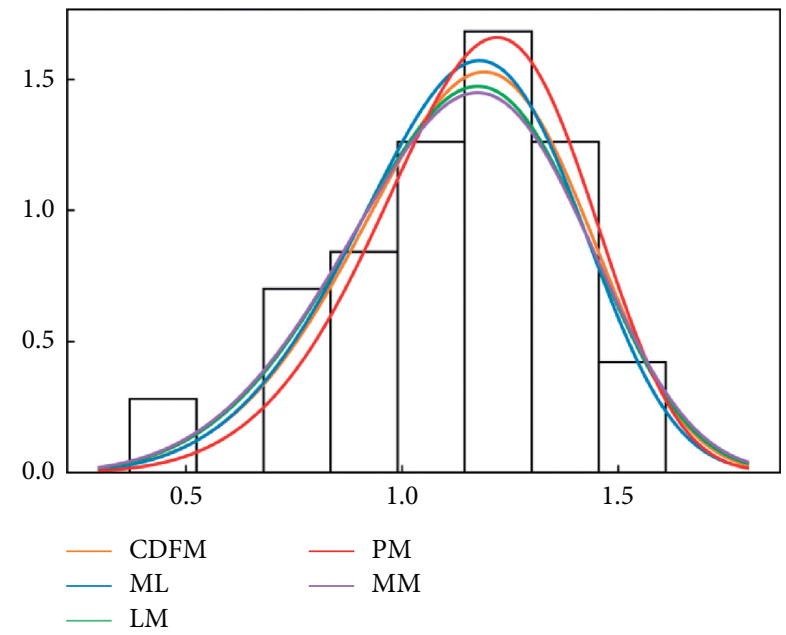

Figure 8: The histogram and the fitted PDFs of the Weibull distributions for sample data set-2.

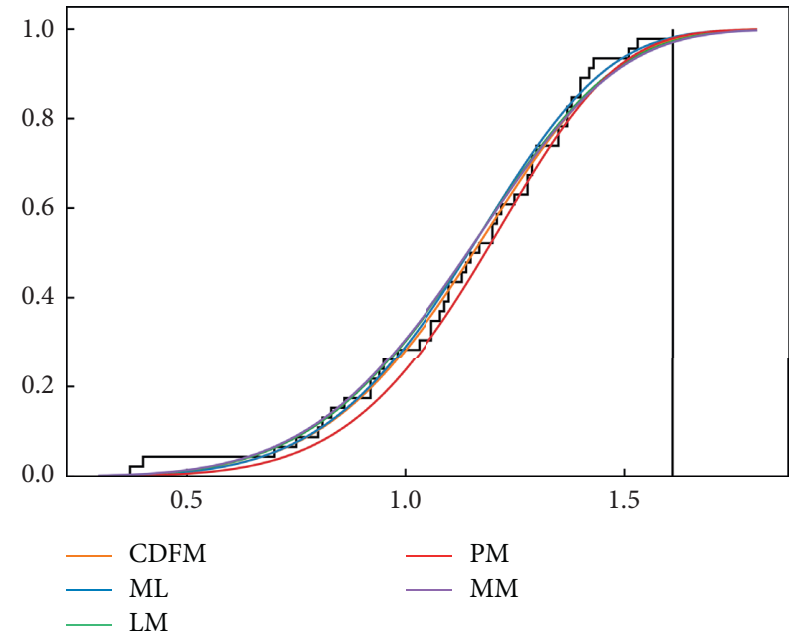

FIgURE 9: Empirical distribution function and the fitted CDFs of the Weibull distributions for sample data set-2. 

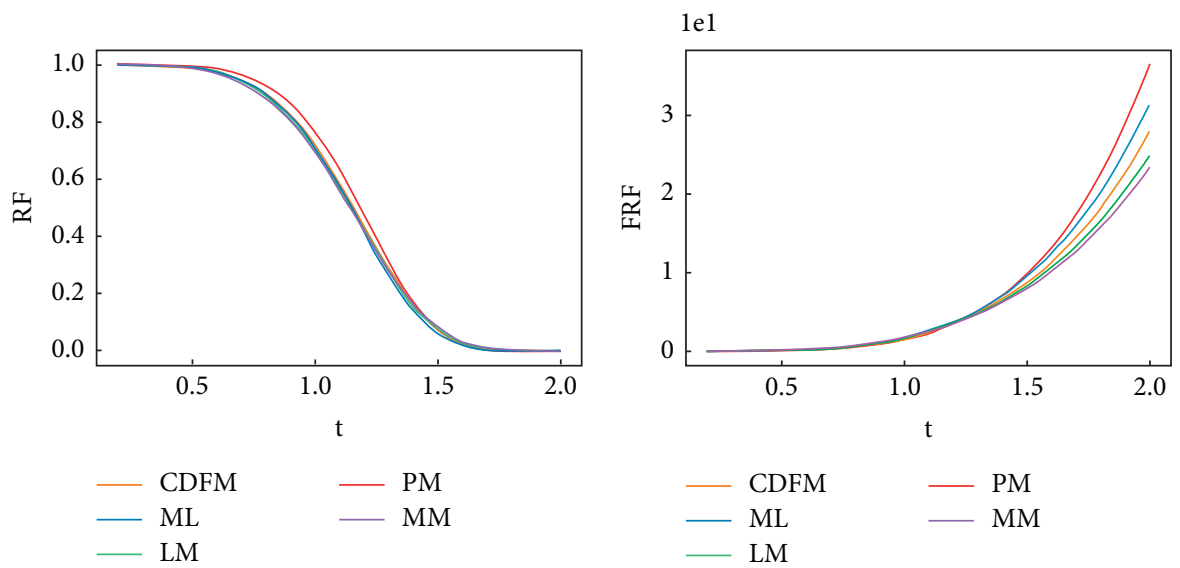

FIGURE 10: The RF and FRF based on different parameter estimation methods for sample data set-2.

\section{Conclusions}

This study aims to solve the problem of parameter estimation for the Weibull distribution and then infer the reliability of products.

6.1. Unique Contributions of the Study. We propose a new parameter estimation method (CDFM) and use this method to estimate the reliability of products. According to Monte Carlo simulation results, it can be found that the CDFM estimation method outperforms the other competitors to obtain reliable estimates of two-parameter Weibull parameters. Therefore, two strength data sets of glass fiber provided by Smith and Naylor [28] are estimated according to the proposed estimation method. The analysis results show that the estimates of CDFM are more suitable for these data sets. And according to the estimates of CDFM, the reliability and failure rate of glass fiber are also estimated. From the analysis results, it can be seen that the reliability and failure rate estimated by different parameter estimates will be different, so it is very important to use a reliable parameter estimate for inference. In addition, the estimation method proposed in this paper can be applied to other fibers, materials, or tests as long as the data follow the Weibull distribution.

6.2. Limitations. In particular, the proposed parameter estimation method can be used as long as the data follows the Weibull distribution, but it cannot guarantee the same performance when the data follows the other distributions.

6.3. Future Research. In the current work, we only consider the parameter estimation and application of two-parameter Weibull distribution without inferring the theoretical properties and limit distribution of the estimators. In future research, in addition to applying this estimation method to other distributions, we can also infer the limit distribution and statistical properties of these estimators. We are currently exploring possible extensions in this direction.

\section{Data Availability}

Two strength data sets of glass fiber were provided by Smith and Naylor (1987).

\section{Conflicts of Interest}

The authors declare that there are no conflicts of interest regarding the publication of this paper.

\section{Acknowledgments}

This work was supported by the Fundamental Research Funds for the Central Universities of China, Program no. JBK2001024.

\section{References}

[1] S. Feih, A. Thraner, and H. Lilholt, "Tensile strength and fracture surface characterisation of sized and unsized glass fibers," Journal of Materials Science, vol. 40, no. 7, pp. 1615-1623, 2005.

[2] R. Sakin and İ. Ay, "Statistical analysis of bending fatigue life data using weibull distribution in glass-fiber reinforced polyester composites," Materials \& Design, vol. 29, no. 6, pp. 1170-1181, 2008.

[3] S. Acitas, C. H. Aladag, and B. Senoglu, "A new approach for estimating the parameters of Weibull distribution via particle swarm optimization: an application to the strengths of glass fibre data," Reliability Engineering \& System Safety, vol. 183, 2019.

[4] Z. Zhu, C. Zhang, S. Meng, and Z. Shi, "A statistical damage constitutive model based on the weibull distribution for alkali-resistant glass fiber reinforced concrete," Materials, vol. 12, no. 12, 2019.

[5] D. C. D. O. N. Ferreira, A. D. S. Ferreira, and S. N. Monteiro, "Weibull analysis of tensile tested piassava fibers with different diameters," Matèria. Revista Internacional d'Art, vol. 23, no. 4, 11 pages, 2018.

[6] S. Alkarni, A. Z. Afify, and I. Elbatal, "The extended inverse weibull distribution: properties and applications," Complexity, vol. 2020, Article ID 3297693, 12 pages, 2020.

[7] H. M. Almongy, E. M. Almetwally, and R. Alharbi, "The weibull generalized exponential distribution with censored 
sample: estimation and application on real data," Complexity, vol. 2021, Article ID 6653534, 15 pages, 2021.

[8] E. M. Almetwally, M. A. H. Sabry, and R. Alharbi, "Marshall-Olkin alpha power weibull distribution: different methods of estimation based on type-I and type-II censoring," Complexity, vol. 2021, Article ID 6653534, 2021.

[9] C. Ferretti, P. Ganugi, and G. Pisano, "Abraded glass strength: an ad hoc fitting protocol based on the change of variable theorem," Mathematical Problems in Engineering, vol. 2020, Article ID 8519426, 12 pages, 2020.

[10] J. Zhao, Z. Ahmad, and E. Mahmoudi, "A new class of heavytailed distributions: modeling and simulating actuarial measures," Complexity, vol. 2021, Article ID 6653534, 18 pages, 2021.

[11] M. Aslam, S. Balamurali, C.-H. Jun, and M. Ahmad, "A twoplan sampling system for life testing under weibull distribution," Industrial Engineering and Management Systems, vol. 9, no. 1, pp. 54-59, 2010.

[12] A. J. Fernández, C. J. Pérez-González, M. Aslam, and C.-H. Jun, "Design of progressively censored group sampling plans for weibull distributions: an optimization problem," European Journal of Operational Research, vol. 211, no. 3, pp. 525-532, 2011.

[13] O. H. Arif and M. Aslam, "A new sudden death chart for the weibull distribution under complexity," Complex \& Intelligent Systems, vol. 32, pp. 1-9, 2021.

[14] M. Aslam, G. Srinivasa Rao, and N. Khan, "Single-stage and two-stage total failure-based group-sampling plans for the Weibull distribution under neutrosophic statistics," Complex \& Intelligent Systems, vol. 7, no. 2, pp. 891-900, 2021.

[15] M. Aslam, "A new failure-censored reliability test using neutrosophic statistical interval method," International Journal of Fuzzy Systems, vol. 21, no. 4, pp. 1214-1220, 2019.

[16] M. Aslam, P. Jeyadurga, and S. Balamurali, "Time-truncated group plan under a weibull distribution based on neutrosophic statistics," Mathematics, vol. 7, no. 10, 2019.

[17] M. Aslam and O. Arif, "Testing of grouped product for the weibull distribution using neutrosophic statistics," Symmetry, vol. 10, no. 9, p. 403, 2018.

[18] C. Zhang, D. Y. Li, and X. P. Kang, "Neutrosophic fusion of rough set theory: an overview," Computers in Industry, vol. 115, Article ID 103117, 2020.

[19] K. Naresh, K. Shankar, and R. Velmurugan, "Reliability analysis of tensile strengths using weibull distribution in glass/ epoxy and carbon/epoxy composites," Composites Part B: Engineering, vol. 133, no. 15, pp. 129-144, 2018.

[20] S. C. Malik, S. K. Chauhan, and N. Ahlawat, "'Reliability analysis of a non series-parallel system of seven components with weibull failure laws," International Journal of Systems Assurance Engineering and Management, vol. 11, no. 1, pp. 577-582, 2020.

[21] X. Jia, "Reliability analysis for weibull distribution with homogeneous heavily censored data based on bayesian and leastsquares methods," Applied Mathematical Modelling, vol. 83, pp. 169-188, 2020.

[22] N. L. Johnson, S. Kotz, and N. Balakrishnan, Continuous Univariate Distributions, Wiley, NewYork, NY, USA, 2nd edition, 1994.

[23] M. Teimouri, S. M. Hoseini, and S. Nadarajah, "Comparison of estimation methods for the Weibull distribution," Statistics, vol. 47, no. 1, pp. 93-109, 2013.

[24] Y. M. Kantar, "Generalized least squares and weighted least squares estimation methods for distributional parameters," Revstat-Statistical Journal, vol. 13, no. 3, pp. 263-282, 2015.
[25] K. C. Datsiou and M. Overend, "Weibull parameter estimation and goodness-of-fit for glass strength data," Structural Safety, vol. 73, pp. 29-41, 2018.

[26] T. Hidekazu, P. Nabendu, and K. L. Wooi, "On improved estimation under Weibull model," Journal of Statistical Theory and Practice, vol. 12, no. 1, pp. 48-65, 2018.

[27] R. H. Byrd, P. Lu, J. Nocedal, and C. Zhu, "A limited memory algorithm for bound constrained optimization," SIAM Journal on Scientific Computing, vol. 16, no. 5, pp. 1190-1208, 1995.

[28] R. L. Smith and J. C. Naylor, "A comparison of maximum likelihood and bayesian estimators for the three- parameter weibull distribution," Applied Statistics, vol. 36, no. 3, pp. 358-369, 1987.

[29] A. L. Morais and W. Barreto-Souza, "A compound class of Weibull and power series distributions," Computational Statistics \& Data Analysis, vol. 55, no. 3, pp. 1410-1425, 2011.

[30] M. Alizadeh, S. Rezaei, and S. F. Bagheri, "On the estimation for the weibull distribution," Annals of Data Science, vol. 2, no. 4, pp. 373-390, 2015.

[31] M. C. Jones and M. J. Faddy, "A skew extension of the $t$ -distribution, with applications," Journal of the Royal Statistical Society: Series B, vol. 65, no. 1, pp. 159-174, 2003. 